\title{
Sex differences of COPD phenotypes in nonsmoking patients
}

\author{
This article was published in the following Dove Press journal: \\ International Journal of COPD \\ 22 July 2016 \\ Number of times this article has been viewed
}

\author{
Yoonki Hong' \\ Wonjun $\mathrm{Ji}^{2}$ \\ Soojeong $\mathrm{An}^{3}$ \\ Seon-Sook Han' \\ Seung-Joon Lee' \\ Woo Jin Kim' \\ 'Department of Internal Medicine, \\ Environmental Health Center, \\ Kangwon National University \\ Hospital, Chuncheon, South Korea, \\ ${ }^{2}$ Department of Pulmonary and \\ Critical Care Medicine, Asan Medical \\ Center, University of Ulsan College \\ of Medicine, Seoul, South Korea, \\ ${ }^{3}$ Department of Statistics, Kangwon \\ National University, Chuncheon, \\ South Korea
}

\begin{abstract}
Background: There is growing evidence about sex-related phenotypes of COPD. However, the sex differences in COPD mainly result from smokers. This study evaluated the sex differences in nonsmoking patients with COPD, focusing on structural changes in the lungs in airway diseases and emphysema.

Methods: Ninety-seven nonsmoking patients, defined as having $<1$ pack-year of lifetime cigarette smoking, diagnosed with COPD were selected from a Korean COPD cohort. Emphysema extent and mean wall area percentage (WA\%) on computed tomography were compared between the male and female groups.

Results: The 97 patients with COPD included 62 females and 35 males. Emphysema index was significantly lower $(3.5 \pm 4.2$ vs $6.2 \pm 5.7, P<0.01)$ and mean WA\% on computed tomography was significantly higher $(71.8 \% \pm 5 \%$ vs $69.4 \% \pm 5 \%, P<0.01)$ in females than in males, after adjusting for age, body mass index, history of biomass exposure, and postbronchodilator forced expiratory volume in 1 second (\% of predicted).

Conclusion: WA\% was higher and emphysema extent was lower in nonsmoking females with COPD than in nonsmoking males with COPD. These findings suggest that males may be predisposed to an emphysema phenotype and females may be predisposed to an airway phenotype of COPD.
\end{abstract}

Keywords: COPD, nonsmoker, emphysema, airway, sex

\section{Introduction}

Although characterized by irreversible airflow limitation, COPD is a heterogeneous disease presenting with various phenotypes. ${ }^{1,2}$ This heterogeneity may result from differences in environmental factors and/or genetic background. Because males and females are exposed to different environmental and genetic factors, there may be sex differences in the clinical presentation of COPD. However, the sex differences in COPD mainly result from smokers.

The prevalence of COPD in females is increasing. Several studies report sex-related differences in clinical characteristics of COPD, including in respiratory symptoms, comorbidities, and outcomes of acute exacerbations, ${ }^{3-7}$ as well as in biomarkers and genetic polymorphisms. ${ }^{8,9}$ Structural changes in the lungs in airway disease and emphysema also differ in males and females. Advances in computed tomography (CT) have allowed for the quantitative assessment of the extent of airway disease and emphysema. Males were associated with a broader extent of emphysema in relation to the cumulative smoking history, ${ }^{10,11}$ whereas, among smokers, females had higher wall area percentage (WA\%) in anatomically matched airways than males. ${ }^{12}$

Sex differences in COPD phenotypes may be more complicated because these studies did not clearly differentiate the effects of sex from the effects of cigarette
Correspondence: Woo Jin Kim Department of Internal Medicine, School of Medicine, Kangwon National University, I Kangwondaehak-gil, Chuncheon, 200-70I, South Korea Tel +82 322589364

Fax +82 322582404

Email pulmo2@kangwon.ac.kr 
smoking or included mainly smokers. The clinical relevance of sex-related phenotypes in COPD is therefore unclear. Determining sex differences in nonsmokers with COPD may be valuable in determining the presentation and clinical course of COPD. Therefore, this study evaluated sex differences in nonsmoking patients with COPD, focusing on structural changes in the lungs in patients with airway disease and emphysema.

\section{Patients and methods}

\section{Patients}

This study analyzed 97 patients with COPD, selected from a Korean cohort. The cohort was developed to observe clinical outcomes of COPD patients living near cement plants in Korea, as previously described. ${ }^{13}$ The cohort recruited patients from 2012 until the end of 2015, with 445 patients recruited till November 2015. Among the 445 patients in the cohort, 335 patients were diagnosed with COPD if they were aged $>45$ years and had a postbronchodilator forced expiratory volume in 1 second $\left(\mathrm{FEV}_{1}\right)$ /forced vital capacity $<0.7$. Among the 335 patients with COPD, 97 patients were selected for this study if they had a cigarette smoking history of $<1$ pack-year (Figure 1).

All patients were evaluated at the enrollment visit by a medical interview, a physical examination, spirometry, laboratory tests, and a CT scan. Initial questionnaire data included demographic characteristics, disease history, environmental exposure, and exacerbation of disease during the previous year. Exacerbations were defined as worsening symptoms (dyspnea, cough, or sputum) requiring treatment with systemic steroids or antibiotics, a visit to the emergency room, and/or admission to a hospital. Dyspnea was evaluated using the modified Medical Research Council (MMRC) dyspnea grade. Health-related quality of life was evaluated

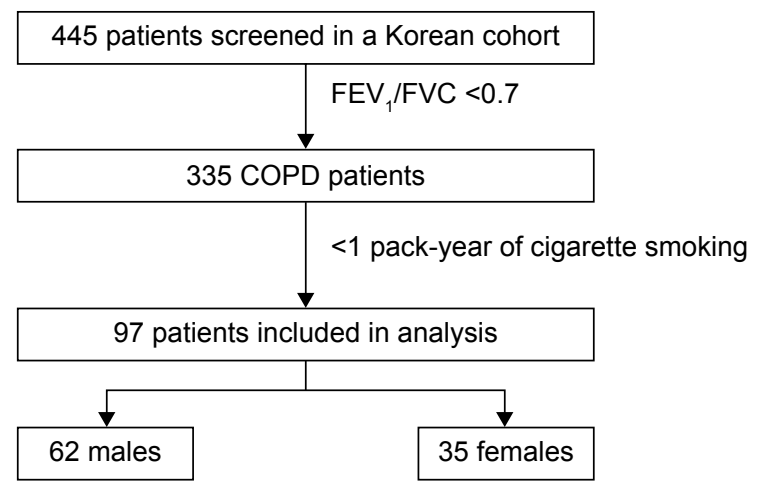

Figure I Selection of study patients from the initial Korean cohort. Abbreviations: $\mathrm{FEV}_{1}$, forced expiratory volume in I second; FVC, forced vital capacity. by calculating the total score on the patient-reported COPD assessment test (CAT). Patients were questioned on their history of direct exposure to biomass using the question, "For cooking and/or heating, have you ever been exposed to fuels of wood or charcoal?", with positive exposure to biomass defined as a direct exposure for $>10$ years.

All pulmonary function tests performed were those recommended by the American Thoracic Society/European Respiratory Society. ${ }^{14}$ Spirometry was performed using an Easy One kit (NDD Medizintechnik AG, Zurich, Switzerland). Increases in postbronchodilator $\mathrm{FEV}_{1}$ were determined by performing spirometry before bronchodilation and 15 minutes after inhalation of $400 \mu \mathrm{g}$ of salbutamol through a metered-dose inhaler with a spacer. Bronchodilator reversibility was evaluated by assessing postbronchodilator $\mathrm{FEV}_{1}$ increase in liters.

Analyses of the clinical and imaging data were approved by the Institutional Review Board of Kangwon National University Hospital (2012, 06-007). All patients provided written informed consent.

\section{Computed tomography}

Volumetric CT scans were performed at full inspiration and expiration using a first-generation dual source CT system (Somatom Definition; Siemens Healthcare, Forchheim, Germany), as described by Lee et al. ${ }^{15}$ Whole-lung images were extracted automatically, and the attenuation coefficient of each pixel was calculated. From CT data, the volume fraction (\%) of the lung below $-950 \mathrm{HU}$ at full inspiration was calculated automatically (emphysema index, EI). The ratio of mean lung density on expiration and inspiration was calculated. Airway dimensions, including wall area (WA), lumen area, and WA\% (ie, WA/[WA + lumen area] $\times 100$ ), were measured near the origin of the right apical and left apicoposterior segmental bronchi. To express the morphologic characteristics quantitatively, we used most frequently used methods, the EI as emphysema extent, and WA\% as airway disease. ${ }^{16,17}$

\section{Statistical analysis}

The baseline characteristics of the patients were reported as mean \pm standard deviation. Normally distributed parameters were analyzed using independent sample $t$-tests, and nonnormally distributed data were analyzed using Mann-Whitney $U$-tests. Multivariate analysis of clinical and CT variables differing in males and females was performed after adjusting for age, body mass index, and postbronchodilator $\mathrm{FEV}_{1}$ (\% of predicted), as age, sex, body mass index, 
and $\mathrm{FEV}_{1}(\%$ of predicted) are associated with the extent of emphysema in smokers with COPD. ${ }^{10,18}$ The history of biomass exposure was also entered into multivariable analysis due to the difference in biomass exposure between females and males, as biomass smoke exposure is associated with less emphysema, suggesting an airway-predominant phenotype. ${ }^{19}$

All statistical analyses were performed using the SAS statistical package, Version 9.2 (SAS Institute Inc., Cary, NC, USA), and SPSS, Version 15 (SPSS Inc., Chicago, IL, USA), with $P$-values $<0.05$ considered statistically significant.

\section{Results \\ Patient characteristics}

Demographic characteristics, lung function, and CT parameters of the 62 females and 35 males with COPD included in this study are shown in Table 1 . Females were significantly older ( $74 \pm 7$ years vs $71 \pm 7$ years, $P=0.04$ ), had a lower body mass index $\left(23.5 \pm 2.9 \mathrm{~kg} / \mathrm{m}^{2}\right.$ vs $\left.25 \pm 3 \mathrm{~kg} / \mathrm{m}^{2}, P=0.015\right)$, and

Table I Baseline characteristics of nonsmoking females and males with COPD

\begin{tabular}{|c|c|c|c|}
\hline Variables & $\begin{array}{l}\text { Females } \\
(n=62)\end{array}$ & $\begin{array}{l}\text { Males } \\
(n=35)\end{array}$ & $P$-value \\
\hline Age, years & $74 \pm 7.2$ & $7 I \pm 7.2$ & 0.04 \\
\hline BMI, kg/m² & $23.5 \pm 2.9$ & $25 \pm 3$ & 0.015 \\
\hline $\begin{array}{l}\text { MMRC dyspnea scale } \\
(0 / I / 2 / 3 / 4)\end{array}$ & $9 / 24 / 6 / 17 / 6$ & $6 / 16 / 6 / 2 / 5$ & 0.13 \\
\hline CAT & $19.4 \pm 10$ & $18 \pm 10.8$ & 0.51 \\
\hline $\begin{array}{l}\text { History of respiratory } \\
\text { disease }(n, \%)\end{array}$ & $32(51.6)$ & $24(68.6)$ & 0.10 \\
\hline $\begin{array}{l}\text { History of tuberculosis } \\
(\mathrm{n}, \%)\end{array}$ & $13(22.4)$ & $5(14.3)$ & 0.34 \\
\hline $\begin{array}{l}\text { History of asthma } \\
(\mathrm{n}, \%)\end{array}$ & $15(26.8)$ & $8(22.8)$ & 0.67 \\
\hline $\begin{array}{l}\text { History of biomass } \\
\text { exposure }(n, \%)\end{array}$ & $33(53.2)$ & $5(14.3)$ & $<0.01$ \\
\hline $\begin{array}{l}\text { History of } \\
\text { exacerbation }(n, \%)\end{array}$ & $6(9.7)$ & $2(5.7)$ & 0.50 \\
\hline $\begin{array}{l}\mathrm{FEV}_{1} / \mathrm{FVC} \\
\text { (median, IQR) }\end{array}$ & $61.8(55-65.7)$ & $62.3(54.7-66.8)$ & 0.94 \\
\hline FVC (\% of predicted) & $104.3 \pm 2||$. & $96.8 \pm 18.5$ & 0.084 \\
\hline $\mathrm{FEV}_{1}(\%$ of predicted) & $84.9 \pm 21.2$ & $80.3 \pm 17.8$ & 0.29 \\
\hline Mean wall area (\%) & $71.8 \pm 5.1$ & $69.4 \pm 5.3$ & 0.027 \\
\hline $\begin{array}{l}\text { Emphysema index } \\
\text { (median, IQR) }\end{array}$ & I.7 (0.7-4.9) & $4.2(1.3-10.4)$ & $<0.01$ \\
\hline Mean lung density ratio & $0.94 \pm 0.05$ & $0.94 \pm 0.03$ & 0.91 \\
\hline
\end{tabular}

Notes: Results are reported as mean \pm standard deviation or as median and IQR and compared by independent sample $t$-tests and Mann-Whitney $U$-tests, respectively. Emphysema index = volume fraction (\%) of the lung below $-950 \mathrm{HU}$, wall area $(\%)=$ wall area/(wall area + lumen area) $\times 100$, and mean lung density ratio $=$ mean lung density ratio of full expiration and inspiration.

Abbreviations: BMI, body mass index; CAT, COPD assessment test; FEV , forced expiratory volume in I second; FVC, forced vital capacity; IQR, interquartile range; MMRC, Modified Medical Research Council.
Table 2 Multivariate analysis of factors associated with sex differences in CT measurements of changes in lung structure in nonsmoking patients with COPD

\begin{tabular}{llll}
\hline CT measurements & Females $(\mathbf{n}=\mathbf{6 2})$ & Males $(\mathbf{n}=\mathbf{3 5})$ & $\boldsymbol{P}$-value \\
\hline Mean wall area $(\%)$ & $71.8 \pm 5.1$ & $69.4 \pm 5.3$ & 0.013 \\
Emphysema index & $3.5 \pm 4.2$ & $6.2 \pm 5.7$ & $<0.01$ \\
MLD ratio & $0.94 \pm 0.05$ & $0.94 \pm 0.03$ & 0.85 \\
\hline
\end{tabular}

Notes: Data are presented as mean \pm standard deviation, after adjusting for age, body mass index, lung function, and history of biomass exposure. Emphysema index = volume fraction (\%) of the lung below $-950 \mathrm{HU}$, wall area (\%) = wall area/ (wall area + lumen area) $\times 100$, and mean lung density ratio $=$ mean lung density ratio of full expiration and inspiration.

Abbreviations: CT, computed tomography; MLD, mean lung density.

were more frequently exposed to biomass ( $53.2 \%$ vs $14.3 \%$, $P<0.01)$ than males. There were no significant differences in dyspnea scale, quality of life (CAT), history of asthma or other respiratory diseases, and lung function.

\section{Sex differences in airway disease and emphysema}

A comparison of CT scan results showed that EI was significantly lower $(3.5 \pm 4.2$ vs $6.2 \pm 5.7, P<0.01)$ and $\mathrm{WA} \%$ significantly higher $(71.8 \pm 5$ vs $69.4 \pm 5.3, P=0.013)$ in females than in males, after adjusting for age, body mass index, FEV ( $\%$ of predicted), and history of biomass exposure (Table 2 ). However, MMRC, CAT, history of exacerbation, and FEV ( $\%$ of predicted) did not differ significantly between males and females after adjusting for age, body mass index, and history of biomass exposure. Two representative cases showing sex differences, a nonsmoking man with diffuse emphysema and a nonsmoking woman with bronchial wall thickening on CT image, are shown in Figure 2.

Therefore, subgroup analysis of CT parameters was performed as a function of history of biomass exposure. Similar trends in sex differences of EI were observed in both subgroups with and without a history of biomass exposure (the Mann-Whitney $U$-test for nonnormally distributed data, $P=0.052$ and $P=0.056$; Table 3 ). In addition, $\mathrm{WA} \%$ was significantly higher in females than in males with a history of biomass exposure $(P<0.01)$, but did not differ significantly in females and males without a history of exposure (Table 4).

\section{Discussion}

This study demonstrated an important structural difference between males and females with COPD, in minimizing influences of cigarette smoking. We found that WA $\%$ was higher and emphysema extent was lower on $\mathrm{CT}$ in nonsmoking females with COPD than in nonsmoking males with COPD, after adjusting for age, body mass index, lung function, and 

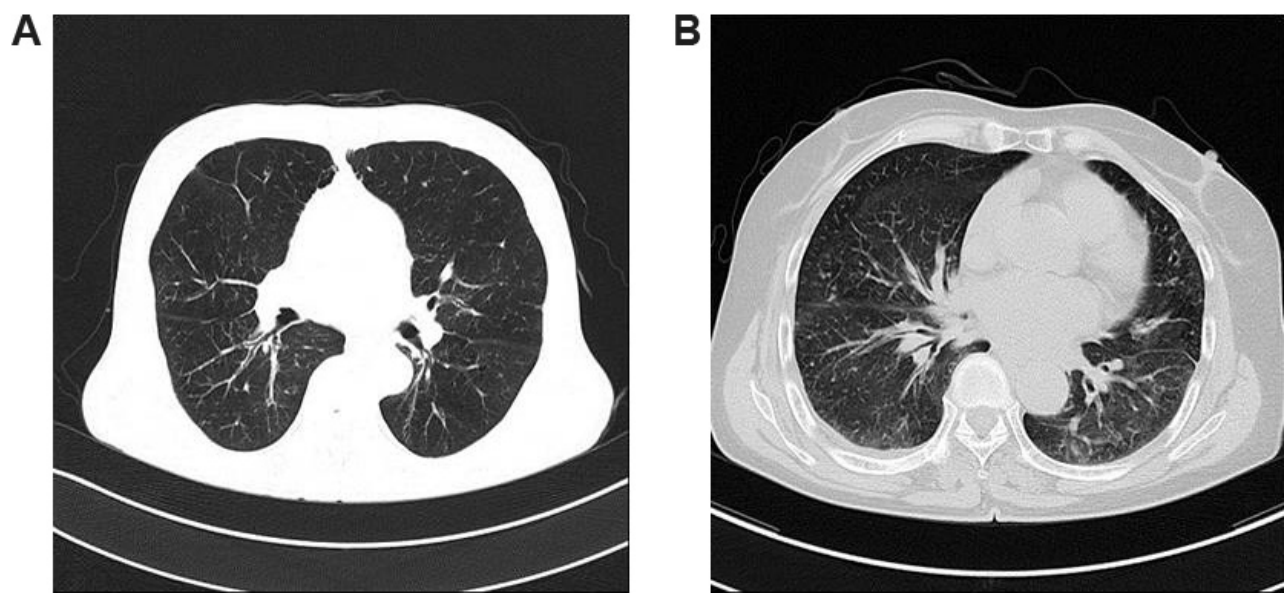

Figure 2 Representative cases showing sex differences on computed tomography (CT) image.

Notes: (A) CT image of 73-year old male having no history of cigarette smoking showing diffuse emphysema. (B) CT image of 8I-year old female having no history of cigarette smoking showing diffuse bronchial wall thickening and no visual emphysema.

biomass exposure. To our knowledge, this study represents the first direct comparison of lung structure phenotypes in nonsmoking males and females with COPD. These sex differences in lung structure may be important for understanding the differences in pathophysiology, development, clinical presentation, and outcomes between males and females with COPD.

Previous studies show that females and males with COPD may present differently and have different patterns of comorbidities and that females may have higher survival rates after acute exacerbations. ${ }^{20}$ The incidence of the two major phenotypes of COPD, airway disease and emphysema, also shows sex differences. Airway disease, as measured by methacholine reactivity, was more common among females than males in the Lung Health Study. ${ }^{21}$ Moreover, CT scans showed that WA $\%$ in anatomically matched airways of smokers was higher in females than in males. ${ }^{12}$ Conversely, the prevalence of emphysema was higher in males than in females, ${ }^{22}$ and $\mathrm{CT}$ results reported higher rates of emphysema in males than in females at all stages of COPD severity. ${ }^{23}$ Taken together, these studies indicate that males are more likely to have emphysema-predominant COPD, whereas females are more likely to have airway-predominant COPD.

Table 3 Subgroup analysis of emphysema index in nonsmoking males and females with COPD with and without a history of biomass exposure

\begin{tabular}{llll}
\hline CT measurements & Females & Males & P-value \\
\hline \multicolumn{2}{l}{ Emphysema index (median, IQR) } & & \\
With biomass exposure & $2.3(0.8-4.8)$ & $5.9(3.5-10.1)$ & 0.052 \\
Without biomass exposure & I.5 (0.4-4.9) & $3.8(1.3-10.4)$ & 0.056 \\
\hline
\end{tabular}

Notes: Data are presented as median with IQRs. Emphysema index = volume fraction (\%) of the lung below $-950 \mathrm{HU}$.

Abbreviations: IQR, interquartile range; CT, computed tomography.
Our results are consistent with these findings, in that WA\% was higher and emphysema extent was lower in females with COPD than in males with COPD. However, earlier results showing sex differences in COPD may have been confounded by the effects of exposure to cigarette smoke and/or biomass. The present study showed sex differences in COPD in nonsmokers, after adjusting for history of biomass exposure.

Since many deaths in males and females with COPD can be attributed to cigarette smoking, ${ }^{24}$ most studies in patients with COPD recruited individuals with at least 10 pack-years of cigarette smoking, concentrating on the role of smoking in COPD. No clear consensus has been reached on the clinical relevance of COPD in nonsmokers because of limited data on the clinical features of COPD in these patients. ${ }^{25,26} \mathrm{As}$ CT scans are more frequently used to characterize COPD, radiologic differences have been observed between smokers and nonsmokers with COPD. The incidence of emphysema on CT scans was lower in nonsmokers than in smokers with COPD. ${ }^{27}$ Thus, previous studies showing that males are more likely to have emphysema-predominant COPD may be associated with the greater incidence of smoking among males. In contrast, females were more susceptible to the damaging effects of cigarette smoke. ${ }^{28,29}$ At present, the

Table 4 Subgroup analysis of the extent of airway disease in nonsmoking males and females with COPD with and without a history of biomass exposure

\begin{tabular}{lccc}
\hline $\mathbf{C T}$ measurements & Females & Males & $P$-value \\
\hline Mean wall area (\%) & & & \\
With biomass exposure & $72.2 \pm 5.6$ & $65 \pm 4.8$ & 0.02 \\
Without biomass exposure & $71.4 \pm 4.5$ & $70.1 \pm 5$ & 0.18 \\
\hline
\end{tabular}

Notes: Data are presented as mean \pm standard deviation, after adjusting for age, body mass index, lung function, and history of biomass exposure. Wall area (\%) = wall area/(wall area + lumen area) $\times 100$.

Abbreviation: CT, computed tomography. 
complex relationship between cigarette smoking and sex in the presentation of COPD cannot be determined because of the lack of clinical data. The present study found that emphysema was more frequent in nonsmoking males with COPD than in nonsmoking females with COPD. These findings may lead to greater understanding of COPD phenotypes, including differentiating the effects of sex from those of cigarette smoking.

Biomass smoke is an important risk factor for the development of COPD. ${ }^{30,31}$ COPD patients exposed to biomass smoke had similar clinical presentations, but less severe lung function, compared with smokers with COPD.${ }^{32}$ Exposure to biomass smoke is associated with a lower rate of emphysema but more air trapping than exposure to tobacco smoke. ${ }^{19}$ As COPD patients exposed to biomass were more likely to be female, ${ }^{32}$ reports that females are more likely to have airway-predominant COPD may be related to the effects of biomass smoke exposure. However, little is known about the relationships among sex, biomass exposure, and COPD phenotypes. The present study showed that WA\% was higher in nonsmoking females with COPD than in nonsmoking males with COPD, after adjusting for history of biomass exposure and that $\mathrm{WA} \%$ was higher in females than males with a history of biomass exposure, but that WA\% was similar in females and males without a history of biomass exposure. These findings suggest that the airway phenotype of COPD is more common in females, and that females may be more susceptible to the damaging effects of biomass smoke in the development of airway disease.

The sex difference in COPD may result from behavioral and/or environmental factors or biologic and/or genetic factors. As previous studies of sex differences in COPD were conducted primarily in smokers, these sex differences could be ascribed to differences in smoking habits and/or susceptibility to tobacco smoke, despite biologic and/or genetic differences between males and females. ${ }^{29}$ More recently, however, smoking behavior tends to be similar in males and females. ${ }^{33}$ Thus, reported sex differences in clinical features of COPD may not be consistently, if not precisely, adjusting the effects of cigarette smoking. Our results suggest that sex differences in the structural characteristics of the airways and parenchyma are not driven by sex differences in cigarette smoking or susceptibility to the effects of cigarette smoke. Broader understanding on sex differences in the pathophysiology of COPD may help in designing sex-based diagnostic and treatment strategies.

This study had several limitations. First, as it was a cross-sectional analysis, the causal relationship between sex and structural changes in the lungs over time could not be determined. Further longitudinal studies are needed to clarify this relationship. Second, there were no comparisons with normal groups, suggesting the need for studies comparing nonsmoking males and females with those with and without COPD. Third, the intensity and duration of previous environmental exposure may not be quantitatively accurate because they were based on participant memory and questionnaires. A long-term follow-up study using exposure metrics is warranted. Fourth, the results of this study may not be generalized because the influence of smoking is not totally excluded, the patients could be influenced by cement dust, and this study relies on CT image analysis and lacks visual evaluation of CT scan. More large-scale or population-based studies will help in identifying sex differences, excluding smoking effects on patients with COPD.

\section{Conclusion}

This study showed important structural differences in the lung parenchyma and airways between nonsmoking males with COPD and nonsmoking females with COPD. WA\% might be higher and emphysema extent was lower in nonsmoking females than in nonsmoking males. These findings suggest that males may be predisposed to develop an emphysema phenotype of COPD, regardless of exposure to cigarette smoke.

\section{Acknowledgments}

This study was supported by a grant from the Ministry of Environment, Republic of Korea. The abstract of this paper was presented at Airway Vista 2016, March 26 and 27, 2016, Seoul, Korea, as a poster presentation with interim findings. The poster's abstract was published in "Poster Abstracts" in Respirology: Abstracts of the Airway Vista 2015, 21-22 March 2015, Seoul, Korea. 2016;21(Suppl S1):13-19.

\section{Disclosure}

The authors report no conflicts of interest in this work.

\section{References}

1. Han MK, Agusti A, Calverley PM, et al. Chronic obstructive pulmonary disease phenotypes: the future of COPD. Am J Respir Crit Care Med. 2010;182(5):598-604.

2. Vestbo J, Hurd SS, Agustí AG, et al. Global strategy for the diagnosis, management, and prevention of chronic obstructive pulmonary disease: GOLD executive summary. Am J Respir Crit Care Med. 2013;187(4): 347-365.

3. Agusti A, Calverley PM, Celli B, et al; Evaluation of COPD Longitudinally to Identify Predictive Surrogate Endpoints (ECLIPSE) Investigators. Characterization of COPD heterogeneity in the ECLIPSE cohort. Respir Res. 2010;11:122.

4. Celli B, Vestbo J, Jenkins CR, et al; Investigators of the TORCH Study Sex differences in mortality and clinical expressions of patients with chronic obstructive pulmonary disease: the TORCH experience. Am J Respir Crit Care Med. 2011;183(3):317-322. 
5. Ekström MP, Jogréus C, Ström KE. Comorbidity and sex-related differences in mortality in oxygen-dependent chronic obstructive pulmonary disease. PLoS One. 2012;7(4):e35806.

6. Gonzalez AV, Suissa S, Ernst P. Gender differences in survival following hospitalisation for COPD. Thorax. 2011;66(1):38-42.

7. Watson L, Schouten JP, Lofdahl CG, et al; European Respiratory Society Study on Chronic Obstructive Pulmonary Disease. Predictors of COPD symptoms: does the sex of the patient matter? Eur Respir J. 2006;28(2): 311-318.

8. de Torres JP, Casanova C, Pinto-Plata V, et al. Gender differences in plasma biomarker levels in a cohort of COPD patients: a pilot study. PLoS One. 2011;6(1):e16021.

9. Kim WJ, Wood AM, Barker AF, et al. Association of IREB2 and CHRNA3 polymorphisms with airflow obstruction in severe alpha-1 antitrypsin deficiency. Respir Res. 2012;13:16.

10. Camp PG, Coxson HO, Levy RD, et al. Sex differences in emphysema and airway disease in smokers. Chest. 2009;136(6):1480-1488.

11. Grydeland TB, Dirksen A, Coxson HO, et al. Quantitative computed tomography: emphysema and airway wall thickness by sex, age and smoking. Eur Respir J. 2009;34(4):858-865.

12. Kim YI, Schroeder J, Lynch D, et al; Copdgene Investigators. Gender differences of airway dimensions in anatomically matched sites on CT in smokers. COPD. 2011;8(4):285-292.

13. Hong Y, Kwon JW, Lee SA, et al. Methodology of an observational cohort study for subjects with chronic obstructive pulmonary disease in dusty areas near cement plants. J Pulm Respir Med. 2014;4:169.

14. Miller MR, Hankinson J, Brusasco V, et al; ATS/ERS Task Force. Standardisation of spirometry. Eur Respir J. 2005;26(2):319-338.

15. Lee YK, Oh YM, Lee JH, et al; KOLD Study Group. Quantitative assessment of emphysema, air trapping, and airway thickening on computed tomography. Lung. 2008;186(3):157-165.

16. Nakano Y, Muro S, Sakai H, et al. Computed tomographic measurements of airway dimensions and emphysema in smokers. Correlation with lung function. Am J Respir Crit Care Med. 2000;162(3 pt 1):1102-1108.

17. Hasegawa M, Nasuhara Y, Onodera Y, et al. Airflow limitation and airway dimensions in chronic obstructive pulmonary disease. Am J Respir Crit Care Med. 2006;173(12):1309-1315.

18. Gu S, Li R, Leader JK, et al. Obesity and extent of emphysema depicted at CT. Clin Radiol. 2015;70(5):e14-e19.

19. Camp PG, Ramirez-Venegas A, Sansores RH, et al. COPD phenotypes in biomass smoke- versus tobacco smoke-exposed Mexican women. Eur Respir J. 2014;43(3):725-734.

20. Aryal S, Diaz-Guzman E, Mannino DM. COPD and gender differences: an update. Transl Res. 2013;162(4):208-218.
21. Kanner RE, Connett JE, Altose MD, et al. Gender difference in airway hyperresponsiveness in smokers with mild COPD. The Lung Health Study. Am J Respir Crit Care Med. 1994;150(4):956-961.

22. Wang Q, Takashima S, Wang JC, Zheng LM, Sone S. Prevalence of emphysema in individuals who underwent screening CT for lung cancer in Nagano prefecture of Japan. Respiration. 2001;68(4):352-356.

23. Dransfield MT, Washko GR, Foreman MG, Estepar RS, Reilly J, Bailey WC. Gender differences in the severity of CT emphysema in COPD. Chest. 2007;132(2):464-470.

24. Whittemore AS, Perlin SA, DiCiccio Y. Chronic obstructive pulmonary disease in lifelong nonsmokers: results from NHANES. Am J Public Health. 1995;85(5):702-706.

25. Eisner MD, Anthonisen N, Coultas D, et al; Committee on Nonsmoking COPD, Environmental and Occupational Health Assembly. An official American Thoracic Society public policy statement: novel risk factors and the global burden of chronic obstructive pulmonary disease. Am J Respir Crit Care Med. 2010;182(5):693-718.

26. Chilvers ER, Lomas DA. Diagnosing COPD in non-smokers: splitting not lumping. Thorax. 2010;65(6):465-466.

27. Tan WC, Sin DD, Bourbeau J, et al; CanCOLD Collaborative Research Group. Characteristics of COPD in never-smokers and ever-smokers in the general population: results from the CanCOLD study. Thorax. 2015;70(9):822-829.

28. Varkey AB. Chronic obstructive pulmonary disease in women: exploring gender differences. Curr Opin Pulm Med. 2004;10(2):98-103.

29. Gan WQ, Man SF, Postma DS, Camp P, Sin DD. Female smokers beyond the perimenopausal period are at increased risk of chronic obstructive pulmonary disease: a systematic review and meta-analysis. Respir Res. 2006;7:52.

30. Orozco-Levi M, Garcia-Aymerich J, Villar J, Ramírez-Sarmiento A, Antó JM, Gea J. Wood smoke exposure and risk of chronic obstructive pulmonary disease. Eur Respir J. 2006;27(3):542-546.

31. Pérez-Padilla R, Regalado J, Vedal S, et al. Exposure to biomass smoke and chronic airway disease in Mexican women: a case-control study. Am J Respir Crit Care Med. 1996;154(3 Pt 1):701-706.

32. Ramírez-Venegas A, Sansores RH, Pérez-Padilla R, et al. Survival of patients with chronic obstructive pulmonary disease due to biomass smoke and tobacco. Am J Respir Crit Care Med. 2006;173(4): 393-397.

33. Thun MJ, Carter BD, Feskanich D, et al. 50-year trends in smoking-related mortality in the United States. N Engl J Med. 2013;368(4):351-364.
International Journal of COPD

\section{Publish your work in this journal}

The International Journal of COPD is an international, peer-reviewed journal of therapeutics and pharmacology focusing on concise rapid reporting of clinical studies and reviews in COPD. Special focus is given to the pathophysiological processes underlying the disease, intervention programs, patient focused education, and self management protocols.

\section{Dovepress}

This journal is indexed on PubMed Central, MedLine and CAS. The manuscript management system is completely online and includes a very quick and fair peer-review system, which is all easy to use. Visit http://www.dovepress.com/testimonials.php to read real quotes from published authors. 